\title{
Can genetic discoveries for age-at-first-birth predict disinhibitory behaviours?
}

\section{By Dr. Jessica K Edwards}

Being pregnant for the first time at a young age is associated with disinhibitory behaviours, such as low self-control, antisocial behaviour and substance misuse. ${ }^{1-3} \mathrm{~A}$ recent genome wide association study (GWAS) demonstrated that genes have a role in these associations. ${ }^{4}$ Now, researchers have tested the hypothesis that molecular-genetic influences on age-atfirst-birth can predict disinhibition.
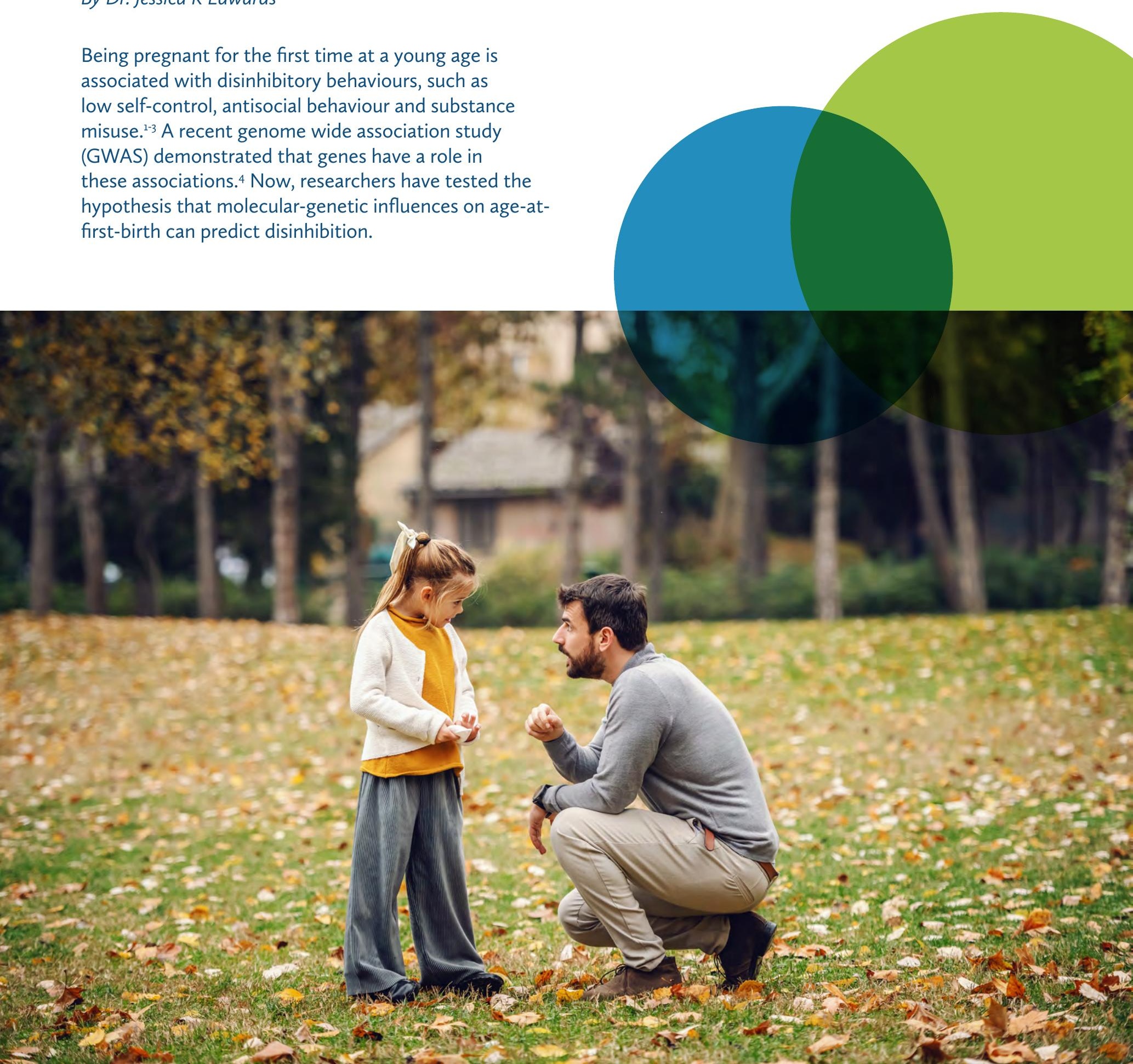


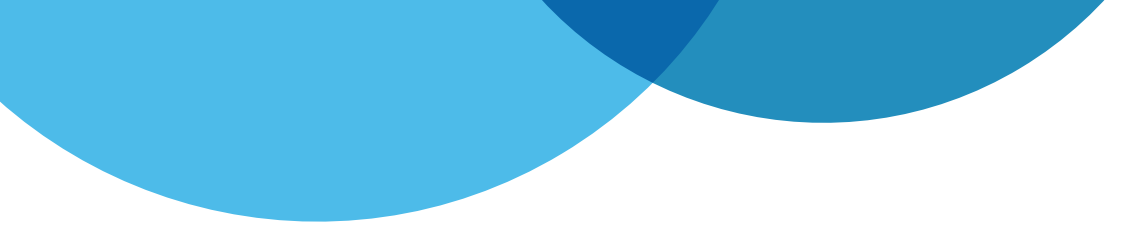

Leah Richmond-Rakerd and colleagues included nearly 3,000 participants with genotype data from the longitudinal Environmental Risk (E-Risk) $)^{5}$ and Dunedin ${ }^{6}$ studies in their analysis. They calculated the polygenic risk score for age-at-first-birth and tested whether it was associated with disinhibitory outcomes across the participants' lives. In both cohorts, the polygenic risk score modestly predicted low childhood self-control, externalizing psychopathology, criminal offending, substance dependence, and the number of sexual partners. Childhood disinhibition partly mediated the associations between the polygenic score and reproductive behaviours.

"Our findings suggest that age-at-first-birth is a useful measure, not just for researchers who are interested in the genetics of reproductive behaviour, but also for researchers who are interested in the genetics of disinhibition", explains Richmond-Rakerd. "Going forward, an important goal for future work is to identify the mechanisms that connect molecular-genetic discoveries for age-at-first-birth with disinhibitory behaviours".

Referring to:

Richmond-Rakerd, L.S., Moffitt, T.E., Arseneault, L., Belsky, D.W., Connor, J., Corcoran, D.L., Harrington, H., Houts, R.M., Poulton, R., Prinz, J.A., Ramrakha, S., Sugden, K., Wertz, J., Williams, B.S. \& Caspi, A. (2020), A polygenic score for age-at-first-birth predicts disinhibition. J. Child Psychol. Psychiatr. doi: 10.111/jcpp.13224.

\section{References:}

${ }^{1}$ Klein, J.D. et al. (2005). Adolescent pregnancy: Current trends and issues. Paediatrics. 116:281-286. doi: 10.1542/peds.2005-0999.

${ }^{2}$ Coyne, C.A. et al. (2012). Some (but not much) progress toward understanding teenage childbearing: a review of research from the past decade. Adv. Child Dev. Behav. 42:113-152. doi: 10.1016/ b978-0-12-394388-0.00004-6.

${ }_{3}^{3}$ Moffitt, T.E. et al. (2011). A gradient of childhood self-control predicts health, wealth, and public safety. Proc. Natl. Acad. Sci. USA. 108:2693-2698. doi: 10.1073/pnas.1010076108.

${ }^{4}$ Barban, N. et al (2016). Genome-wide analysis identifies 12 loci influencing human reproductive behaviour. Nat. Genet. 49:14621475. doi: 10.1038/ng.3698

${ }_{5}^{5}$ Moffitt, T.E. et al. (2002). Teen-aged mothers in contemporary Britain. J. Child Psychol. Psychiatr. 43: 727-742. doi: 10.1111/14697610.00082.

${ }^{6}$ Poulton, R. et al. (2015), The Dunedin Multidisciplinary Health and Development Study: Overview of the first 40 years, with an eye to the future. Social Psychiatry \& Psychiatric Epidemiology, 50:679-693.

\section{Glossary:}

Disinhibition: the inability to suppress inappropriate or unwanted behaviours. Affected individuals might show a lack of restraint or regard for social norms, or participate in unnecessarily risky or dangerous activities.

\section{Polygenic risk score: a} quantification of the cumulative effects of a number of genetic variants (which might individually have very small effects on susceptibility) on a particular trait with a genetic component. 